\title{
Connecting the CMU Community with PE/VC Data: Positioning CMU Libraries as a Strategic Partner for Entrepreneurship
}

\author{
RYAN SPLENDA \\ Carnegie Mellon University, Pittsburgh, PA \\ rsplenda@andrew.cmu.edu
}

\begin{abstract}
Entrepreneurial research is quickly becoming one of the major forces on campus at Carnegie Mellon University (CMU). The newly created Swartz Center for Entrepreneurship as well as various classes and programs devoted to innovation in healthcare and technology at the Tepper School of Business and College of Engineering, have created an environment where faculty, students, and staff are encouraged to pursue entrepreneurial projects. As a result, there is an ever increasing demand for private equity (PE) and venture capital (VC) data for benchmarking, competitive intelligence, and startup research. In response to this, our goal is to position CMU Libraries as a strategic partner with those entities on campus that need this data and expertise. This paper will discuss the acquisition of data sources, the development of presentations and workshops on this type of data, and the different groups on campus with whom the libraries collaborate in this space. Next steps include an environmental scan and forming a commercialization team of librarians dedicated to these research efforts.
\end{abstract}

Keywords private equity, venture capital, entrepreneurship, collaboration, data

\section{Introduction}

An explosion of entrepreneurship research within the literature has occurred over the last 30 years. According to Ferreia, Reis, and Miranda ( $\underline{2015}), 0.2 \%$ of articles published in the top journals in 1982 were entrepreneurial in focus. That number has increased to $11.6 \%$ in 2010 . This ongoing trend has been fueled by the founding of new outlets, research centers, and masters and doctoral studies programs on entrepreneurship, and the ability of entrepreneurship scholars to take their research into the top tier management journals. This trend is also evident at Carnegie Mellon University (CMU). Recently, CMU launched the Swartz Center for Entrepreneurship, which is the major center on campus for all entrepreneurship research and endeavors. Additionally, many of the schools have begun to offer more classes on innovation, entrepreneurship, and private equity/venture capital. This is most evident with the Tepper School of Business and the College of Engineering.

Because of the ever increasing efforts around entrepreneurial research and endeavors at CMU, it is necessary for CMU Libraries to stake a claim as a strategic partner in these ventures. There has been a noticeable increase in both the number of classes that are taught about PE/VC, as well as questions from different members across campus about this type of data. Some recent examples from both faculty and students include, "What is the total VC funding in the biotech sphere?", "How can I access PrivCo and Thomson PE/VC data for a comparison paper?", and "Does CMU have access to PitchBook or CB Insights?".

This article will describe a four-part plan that focuses on connecting CMU researchers with PE/VC data and other resources that will lead to the positioning of the Libraries as a strategic partner for all 
entrepreneurship activities. The four-part plan includes identifying and acquiring additional PE/VC data sources, developing appropriate class presentations and workshops, performing an environmental scan to identify additional stakeholders/collaborators, and creating a commercialization team of librarians that focuses on entrepreneurship activities.

\section{Acquiring Data Sources}

Due to the influx of research efforts around PE, VC, and entrepreneurship on the campus of CMU, it was necessary for the library to acquire additional data sources to aid in the research efforts of those working in this space. Much like the recent explosion of entrepreneurship literature, there has been a number of new vendors that focus on PE and VC data that are now available in addition to the many traditional vendors of this data. My colleague at the University of Pennsylvania, Marcella Barnhart, and I (2017) examined which data sources business and entrepreneurship faculty are using in this sphere. There are seven sources that are primarily being used for PE/VC data: PrivCo, S\&P Capital IQ, PitchBook, CB Insights, VentureSource/VentureXpert (Thomson Reuters), Zephyr (Bureau van Dijk), and Preqin. The first step of the plan was to evaluate and acquire additional resources for the CMU community, and it was decided to further evaluate S\&P Capital IQ, CB Insights, Preqin, and PitchBook.

The evaluation period for all four resources took a little over a year. Given that there is no separate Business Library at CMU, it is essential to provide as much access as possible for the entire CMU community. This can often be a challenge with business information resources as many require individual terminals for accessing content, or require that the resource be limited to the business school community on campus. After vetting all four resources, it was determined that S\&P Capital IQ and CB Insights would provide the additional data necessary for the entrepreneurial community on campus. Although PitchBook and Preqin are valuable resources in their own right, their pricing, access, and data downloading models were not ideal for the given circumstances at CMU.

Given the access challenges involved with S\&P Capital IQ, expanded access via computer terminals to this resource was necessary at CMU to help support additional areas outside of PE/VC, mainly finance and quantitative finance. Many of the top business schools in the country have access to this resource for these purposes. After a trial period with S\&P Capital IQ, the Libraries added additional seats for this resource with the financial support of the Tepper School, and it is now available to other stakeholders on campus via library-based terminals.

The evaluation and comparison of CB Insights and PitchBook was of key interest. Both resources are increasing in popularity and are among the most sought after by business and entrepreneurship faculty and students because of their strengths in private company information and financing data. The two most important factors under consideration were campus-wide access to the database and a reasonable amount of downloads for academic research. CB Insights does allow for these capabilities and PitchBook does not, which was the final deciding factor when choosing between the two. To date, both S\&P Capital IQ and CB Insights have been fully integrated into the library's database offerings and have received positive usage. CB Insights usage data has been particularly positive. Within the first six months of subscribing, over 200 users from across campus have signed up for accounts, and over 1,000 searches and 4,000 downloads have been executed. 


\section{Developing Presentations \& Workshops}

After adding additional PE/VC resources, the second step involved creating presentations and workshops for targeted PE, VC, and entrepreneurship classes and programs. The three areas on campus that work with this type of data the most at this time are the Tepper School of Business, Swartz Center for Entrepreneurship, and the Engineering \& Public Policy Department in the College of Engineering. Creating class-specific presentations that focus on these resources for assignments further enhances the collaborative relationship between CMU Libraries and the faculty and students that need these data, as well as strengthens the goal of positioning the Libraries as a strategic partner in entrepreneurial endeavors.

The two Tepper classes that were immediately targeted are Entrepreneurial Alternatives and Venture Capital \& Private Equity. The Entrepreneurial Alternatives class focuses on the tactical elements of business acquisition and franchise purchase including target evaluation, financial analysis of targets, business valuation, deal structuring, financing of purchases, and post-purchase operations and integration. Essentially, this class teaches entrepreneurship through acquisition. The PE/VC resources are essential for this class when examining deal structures and business valuations. The key takeaway for the class assignment is to create a list of target companies based on certain criteria of interest that can be examined and evaluated by the students in the class. The VC \& PE class focuses on the transactions themselves, which are often risky, complex, and highly customized for the particulars of the situation. A great deal of time and attention is paid to the VC firm and the entrepreneurial startup, which is why the additional resources that were acquired are extremely valuable for this class.

The Swartz Center for Entrepreneurship is the main center on campus for entrepreneurial education and activities. Their Swartz CONNECTS series allows for the entire CMU community to learn from various specialists in the entrepreneurship world. CMU Libraries are fortunate to be involved in this series and I deliver two presentations during the year. One presentation focuses on Customer and Competitive Discovery via Secondary Market Databases. Students and entrepreneurs learn about the various resources that the Libraries offer for company, industry, and market research. The students spend time during the presentation using the resources for private company information and VC funding. The second workshop is called Finding Follow-on Capital. I co-present with a recent Tepper grad who now works in the healthcare industry. This presentation focuses on using some of the same tools that investment bankers and venture capitalists use when targeting next round investors. Again, this is where the new PE and VC resources are exposed and explored.

The College of Engineering's Engineering and Public Policy Department has increasingly offered classes on innovation and entrepreneurship for the technology and energy spheres. Two classes in particular have focused on the PE/VC and market research components-Energy Innovation and Entrepreneurship and Quantitative Entrepreneurship: Analysis of New Technology Commercialization. I work with both of these classes to explain and teach the value of doing competitive intelligence research with the PE/VC resources. This includes identifying competitors that operate within industries of interest and examining their financing. The addition of the CB Insights database has been essential for these classes because this vendor does focus on very niche, new, and emerging markets and sectors that are often difficult to assess with traditional resources that mainly use less specific industry classification schemes like NAICS and SIC codes. 


\section{Current CMU Collaborations}

As previously discussed, there are ongoing collaborations with the Tepper School, Swartz Center, and the EPP Department. The plan is to further enhance these collaborations by branching out into other classes and eventually to design instructional modules that focus on a variety of entrepreneurial information sources. In addition to these current collaborations, there is another entity on campus that has been instrumental in working with the Libraries to help with campus entrepreneurial projects and research-the Center for Machine Learning and Health (CMLH).

CMLH is one of two centers that launched under the umbrella of the Pittsburgh Health Data Alliance (PHDA) in 2015. The PHDA's goal is to unite CMU's applied computing capabilities, the University of Pittsburgh's health sciences research, and the University of Pittsburgh Medical Center's (UPMC) clinical care and commercialization expertise. CMLH specifically supports science and engineering that can lead to innovative health solutions and new businesses, and is administratively run within the School of Computer Science.

The collaboration started when the Development Officer for Commercialization contacted the library about entrepreneurial resources that focus on startups and PE/VC data. After meeting with the Development Officer, it was determined that the Libraries and CMLH should work together to evaluate and select the appropriate resource that can be both beneficial to CMLH and the entire campus community. CMLH had previously paid for a license to PitchBook, but were growing concerned about the cost of the subscription and the limited access to the resource as it is only available on select computer terminals. I worked very closely with the Development Officer to evaluate PitchBook a bit further as well as the CB Insights database. Our evaluation led to the conclusion that a subscription to the CB Insights database would be the best solution for the needs of both CMLH and the rest of the CMU campus. CMLH also agreed to help pay for part of the subscription, which helped offset the cost of the database for the Libraries. This partnership between CMLH and the Libraries has continued with the renewal of CB Insights database for a second year. It is our goal to build additional relationships like this in the future with other stakeholders on campus.

\section{Next Steps: Environmental Scan \& Creating a Commercialization Team}

Now that additional resources have been acquired and collaborations with stakeholders on campus are underway, the third step of the process is to perform an environmental scan of the rest of campus to identify additional people, programs, and departments that need support in this area. This will involve examining new courses that are being offered in the various schools on campus, as well as identifying faculty members and others who have a research interest in PE/VC and entrepreneurship. We predict that there will be additional departments and centers within the School of Computer Science (SCS) that will be great candidates with whom to forge new partnerships. Specifically, the Robotics Institute and the Machine Learning Department of SCS concentrate their efforts on innovation and entrepreneurship. Another future stakeholder is the Integrated Innovation Institute (III), which is a collaboration between the Tepper School of Business, the College of Engineering, and the College of Fine Art's School of Design. Their mission is to break down the silos that impede innovation by uniting these three disciplines to build impactful solutions that create value for real people. The III continues to increase the number of innovation and entrepreneurship classes for students. 
The final step of the process is to develop a commercialization team of librarians and to form our own center or hub within the Libraries that focuses on entrepreneurial information and expertise. The goal of the team and the center will be to serve as a one-stop shop for entrepreneurial information and research that helps all those at CMU who are interested in commercializing various products and services that they have developed. Given the research strengths of CMU and the types of resources needed for entrepreneurial endeavors, the commercialization team of librarians will have expertise in the following areas: business, healthcare/medicine, computer science, engineering, and law for intellectual property purposes. The idea for this is very similar to the University of Arizona Libraries' Business Intelligence Unit, which is a collaborative effort between the University Libraries and Tech Launch Arizona (the commercialization center for the University of Arizona), as well as Erin Wachowicz, Business \& Management Librarian at Yale University, and her work in creating a small team of librarians focused on entrepreneurship research. The creation and execution of this team and center will cement CMU Libraries as a true, strategic partner in all entrepreneurial activities at $\mathrm{CMU}$, and will break new ground for our unit on campus as a collaborative partner in the research and commercialization efforts of the university.

\section{Conclusion}

Like many universities across the country and the world, CMU continues to expand its research efforts in innovation and entrepreneurship. It is the responsibility of CMU Libraries to respond to this challenge and work as a strategic partner in these efforts. To date, the Libraries are in the early stages of the four-part plan described above, but great progress has been made over the last two years. The Libraries have laid the groundwork to becoming partners in entrepreneurship by adding the additional data sources, S\&P Capital IQ and CB Insights, to our collections. Class presentations and workshops for the Swartz Center for Entrepreneurship, Tepper School of Business, and College of Engineering have been developed and delivered. Performing an environmental scan for additional campus needs and creating a commercialization team of librarians for entrepreneurial endeavors are the next steps in the process.

There are some barriers to consider in executing the second half of the plan. Chief among them are time and personnel. CMU librarians and staff are working at maximum capacity, and the development of a commercialization team and an entrepreneurship center will involve additional time to plan. Job duties for the center and team would have to be reorganized because this would function as its own center within the Libraries that primarily focuses on the needs of all CMU entrepreneurship researchers. An increase in personnel is also necessary for the completion of this plan. Additional librarians with specializations in business/entrepreneurship, engineering, computer science, health/medicine and law will have to be hired to devote the time necessary for the goals of the center. Finally, awareness and support from CMU at-large is essential for the success of this plan. The university administration will need to support this plan both financially and assist in the marketing efforts across the campus community.

Though there are barriers to tackle with the implementation of this plan, the opportunities for positive and meaningful collaborations are endless. The Libraries have the tools and expertise necessary to help advance the entrepreneurial research goals of CMU well into the $21^{\text {st }}$ century. By becoming a strategic partner for entrepreneurship, the Libraries will help define a new role for itself within the CMU community and help CMU as a whole continue its mission for academic and entrepreneurial excellence. 
Ticker: The Academic Business Librarianship Review, 3:2 (2019)

http://dx.doi.org/10.3998/ticker.16481003.0003.203

(C) 2019 Ryan Splenda

\section{References}

Ferreira, M. P., Reis, N. R., \& Miranda, R. (2015). Thirty years of entrepreneurship research published in top journals: Analysis of citations, co-citations and themes. Journal of Global Entrepreneurship Research, 5(1), 1-22. https://doi.org/10.1186/s40497-015-0035-6

Splenda, R., \& Barnhart, M. E. (2017). Venturing forth: Venture capital and private equity information in academic business libraries. Journal of Business \& Finance Librarianship, 22(3-4), 208-221.

https://doi.org/10.1080/08963568.2017.1372013 